\title{
Antagonistic Properties of Some Halophilic Thermoactinomycetes Isolated from Superficial Sediment of a Solar Saltern and Production of Cyclic Antimicrobial Peptides by the Novel Isolate Paludifilum halophilum
}

\author{
Donyez Frikha Dammak, ${ }^{1}$ Ziad Zarai, ${ }^{2}$ Soumaya Najah, ${ }^{3}$ Rayed Abdennabi, ${ }^{4}$ \\ Lassaad Belbahri, ${ }^{4}$ Mostafa E. Rateb, ${ }^{5}$ Hafedh Mejdoub, ${ }^{6}$ and Sami Maalej ${ }^{1}$ \\ ${ }^{1}$ Unité Biodiversité et Ecosystèmes Aquatiques Environnementaux (UR/11ES/72), Faculté des Sciences de Sfax, \\ Université de Sfax, BP 1171, 3000 Sfax, Tunisia \\ ${ }^{2}$ Laboratoire de Biochimie et de Génie Enzymatique des Lipases, ENIS, BPW, 1173 Sfax, Tunisia \\ ${ }^{3}$ Institut de Biologie Integrative, UMR 9198, Université Paris-Sud, Bat 400, 91405 Orsay Cedex, France \\ ${ }^{4}$ Laboratory of Soil Biology, University of Neuchatel, 11 Rue Emile Argand, 2000 Neuchatel, Switzerland \\ ${ }^{5}$ School of Science \& Sport, University of the West of Scotland, Paisley PA1 2BE, UK \\ ${ }^{6}$ Laboratoire des Biotechnologies Végétales Appliquées à l'Amélioration des Cultures, FSS, Université de Sfax, \\ BP 1171, 3000 Sfax, Tunisia \\ Correspondence should be addressed to Sami Maalej; sami.maalej@fss.rnu.tn
}

Received 23 March 2017; Accepted 18 June 2017; Published 27 July 2017

Academic Editor: Pedro J. Garcia-Moreno

Copyright (C) 2017 Donyez Frikha Dammak et al. This is an open access article distributed under the Creative Commons Attribution License, which permits unrestricted use, distribution, and reproduction in any medium, provided the original work is properly cited.

This study has focused on the isolation of twenty-three halophilic actinomycetes from two ponds of different salinity and the evaluation of their ability to exert an antimicrobial activity against both their competitors and several other pathogens. From the 23 isolates, 18 strains showed antagonistic activity, while 19 showed activities against one or more of the seven pathogen strains tested. Six strains exhibited consistent antibacterial activity against Gram-negative and Gram-positive pathogens characterized at the physiological and molecular levels. These strains shared only 94-95\% 16S rRNA sequence identity with the closely related species of the Thermoactinomycetaceae family. Among them, the potent strain SMBg3 was further characterized and assigned to a new genus in the family for which the name Paludifilum halophilum (DSM $102817^{\mathrm{T}}$ ) is proposed. Sequential extraction of the antimicrobial compounds with ethyl acetate revealed that the crude extract from SMBg3 strain had inhibitory effect on the growth of the plant pathogen Agrobacterium tumefaciens and the human pathogens Staphylococcus aureus, Salmonella enterica, Escherichia coli, and Pseudomonas aeruginosa. Based on the HRESI-MS spectral data, the cyclic lipopeptide Gramicidin S and four cyclic dipeptides (CDPs) named cyclo(L-4-OH-Pro-L-Leu), cyclo(L-Tyr-L-Pro), cyclo(L-Phe-L-Pro), and cyclo(L-Leu-L-Pro) were detected in the fermentation broth of Paludifilum halophilum. To our knowledge, this is the first report on the isolation of these compounds from members of the Thermoactinomycetaceae family.

\section{Introduction}

Actinomycetes are considered as an intermediate group of bacteria and fungi and recognized as prokaryotic organisms. Traditionally, these bacteria have been isolated from terrestrial sources although the first report of myceliumforming actinomycetes recovered from marine sediments appeared several decades ago $[1,2]$. It is only recently that marine-derived actinomycetes have become recognized as a source of novel antibiotics and anticancer agents with unusual structures and properties $[3,4]$. However, considering the rising need of new antibiotics to combat the emergence of drug-resistant bacteria, many microbiologists have focused their recent research on actinomycetes from nonconventional environments where particular chemical and physical factors contribute to the selection of species that are best adapted to 
that extreme environment. To cope with their environmental stressful factors, these microorganisms have developed a complex stress management for their survival, which is being unrevealed for multiple purposes $[5,6]$. Accordingly, groups of acidophilic and alkaliphilic, psychrophilic and thermophilic, halophilic and haloalkaliphilic, and xerophilic actinomycetes have been described $[7,8]$.

In recent years, novel halophilic and halotolerant actinomycetes of diverse genera from diverse families have been isolated from hypersaline environments [9-11]. On the basis of phenotypic, chemotaxonomic, and phylogenetic analysis, several of these halophilic strains were affiliated to the Thermoactinomycetaceae family of the phylum Firmicutes, which was created for the first time in 2006 by Matsuo et al. [12] and included six genera named Thermoactinomyces, Laceyella, Thermoflavimicrobium, Seinonella [13], Planifilum [14], and Mechercharimyces [12]. Recently, numerous novel genera, such as Melghirimyces, Salinithrix, and Croceifilum, were added to this family and the number was extended to seventeen $[15,16]$. Except some genera having mesophilic growth below $45^{\circ} \mathrm{C}$, growth in a thermophilic range is a main feature of the Thermoactinomycetaceae family [14]. In addition, several species of the family, such as Melghirimyces algeriensis isolated from an Algerian salt lake [17], Salinithrix halophila from the soil of hypersaline wetland in the north of Iran [18], and Paludifilum halophilum from a superficial sediment of Tunisian solar saltern [16], are halotolerant or halophilic able to support until 20\% (w/v) of salinity. Despite the increasing number of halophilic thermoactinomycetes, these microorganisms are still of the least explored ones for novel secondary metabolites. In the field of antimicrobial substances, only some new antibiotics, such as chinikomycin and lajollamycin, are detected in halophilic or halotolerant actinomycete species [4] and several biotechnology companies and academic institutions are currently working on new strategies for the pharmaceutical applications of these new compounds.

Sfax solar saltern, located in the central east of Tunisia, is one of the largest marine salterns in the region. Even though a number of culture-dependent and culture-independent studies were carried out on the biodiversity of eukaryotic [19] and prokaryotic $[20,21]$ microbial assemblages inhabiting different ponds, there are no reports on any exclusive diversity or biotechnological potential of actinomycetes inhabiting this ecosystem. In a continuous effort to explore the prokaryotic diversity and discover new antimicrobial compounds, we performed a screening procedure to isolate rare halophilic actinomycetes from a concentrator and crystallizer solar saltern ponds and explore their potential to produce drugs against agricultural and human pathogens. The novel isolate Paludifilum halophilum strain SMBg3 with significant antimicrobial activity was characterized further and shown to be potential producer of Gramicidin $S$ and four cyclic antimicrobial dipeptides.

\section{Materials and Methods}

2.1. Study Site and Samples Collection. The study was conducted in the solar saltern of Sfax located in the central eastern coast of Tunisia $\left(34^{\circ} 39^{\prime} \mathrm{N}\right.$ and $\left.10^{\circ} 43^{\prime} \mathrm{E}\right)$. It is an artificial ecosystem consisting of a series of interconnected ponds extending over an area of 1500 ha along $12 \mathrm{~km}$ of coastline (Figure 1). These ponds are shallow $(20-70 \mathrm{~cm}$ deep), with a salinity of between 4 and $43 \%(\mathrm{w} / \mathrm{v})$. The process begins by storing seawater in 17 primary ponds to increase water salinity by evaporation. When the salt concentration reaches the $40-75 \mathrm{~g} / \mathrm{L}$ range, the seawater is moved to an internal section of five parallel water ponds where it is kept until the salt concentration reaches $130 \mathrm{~g} / \mathrm{L}$. After this stage, the seawater is distributed into the six precrystallization ponds to attain a salt concentration of $300 \mathrm{~g} / \mathrm{L}$. At the final stage (crystallizer ponds), where the salt precipitates, the brines reach a very high salt concentration ( 400 to $430 \mathrm{~g} / \mathrm{L}$ ).

Superficial sediment and water samples were taken in December 2012 and February and Mars 2013, from two different salinity ponds, the concentrator pond M1 (salinity $20 \%$ $(\mathrm{w} / \mathrm{v})$ ) and the crystallizer pond TS18 (salinity 38\% (w/v)), and immediately stored cold until processing in laboratory within 2 hours of collection. Salinity of the water samples above the sediment was determined at the site with a hand refractometer (ZUZI 5032020), while $\mathrm{pH}$ and temperature were measured in situ using, respectively, a digital $\mathrm{pH}$-meter (ISTEK NeoMet pH-220L) and a mercury glass thermometer (Nahita 72075150). Samples for dissolved organic carbon (DOC) were filtered through a $0.22 \mu \mathrm{m}$ pore size membrane and the concentrations were measured as $\mathrm{CO}_{2}$ generated by catalytic combustion using a Shimadzu TOC-V carbon analyzer.

2.2. Isolation of Halophilic Actinomycetes. An aliquot of $1 \mathrm{ml}$ of the water sample or $1 \mathrm{~g}$ of the superficial sediment (the $0-2 \mathrm{~cm}$ fraction) treated with double sonication (Ultrasonic Homogenizers Sonopuls HD 2070) was dispersed in $9 \mathrm{~mL}$ of filter sterilized (pore size $0.22 \mu \mathrm{m}$ ) saline water with $15 \%$ $\mathrm{NaCl}$. Additional series of dilution were also made and $0.1 \mathrm{~mL}$ of the proper dilution was spread on the surface of different selective media, namely, Glucose-Tryptone-Yeast (GTY) [22], Starch Casein Agar (SCA) [23], Bennett medium [24], complex medium (CA) [24], ISP2, and Bergey's Streptomyces medium [25]. Each medium was supplemented with $0.2 \mu \mathrm{m}$ pore size filtered cycloheximide $(25 \mu \mathrm{g} / \mathrm{mL})$ and nalidixic acid $(25 \mu \mathrm{g} / \mathrm{mL})$ and $15 \%(\mathrm{w} / \mathrm{v}) \mathrm{NaCl}$.

The aerobic development and growth characteristics of halophilic actinomycetes were followed daily at $37^{\circ} \mathrm{C}$ on plates and colonies were recognized by their characteristic chalky leather appearance and their severe and dry appearance. After four weeks of growth, colonies were counted and twenty-three, with diverse morphologies, pigmentation, and sizes, were randomly selected from the different media, subcultured several times on their isolation media to obtain pure cultures, and stored at $-80^{\circ} \mathrm{C}$ in $20 \%(\mathrm{v} / \mathrm{v})$ glycerol. A code of three letters and one number was assigned for each strain: the first letter of $\mathrm{S}$ and $\mathrm{W}$ refers, respectively, to the sediment or water origin of the strain; the second letter corresponds to the isolation pond: T (for TS18 pond) and $\mathrm{M}$ (for $\mathrm{M} 1$ pond); the third letter designates the isolation medium: B (for Bennett medium), G (for GTY medium), Bg (Bergey's medium), C (for CM medium), S (for SCA 

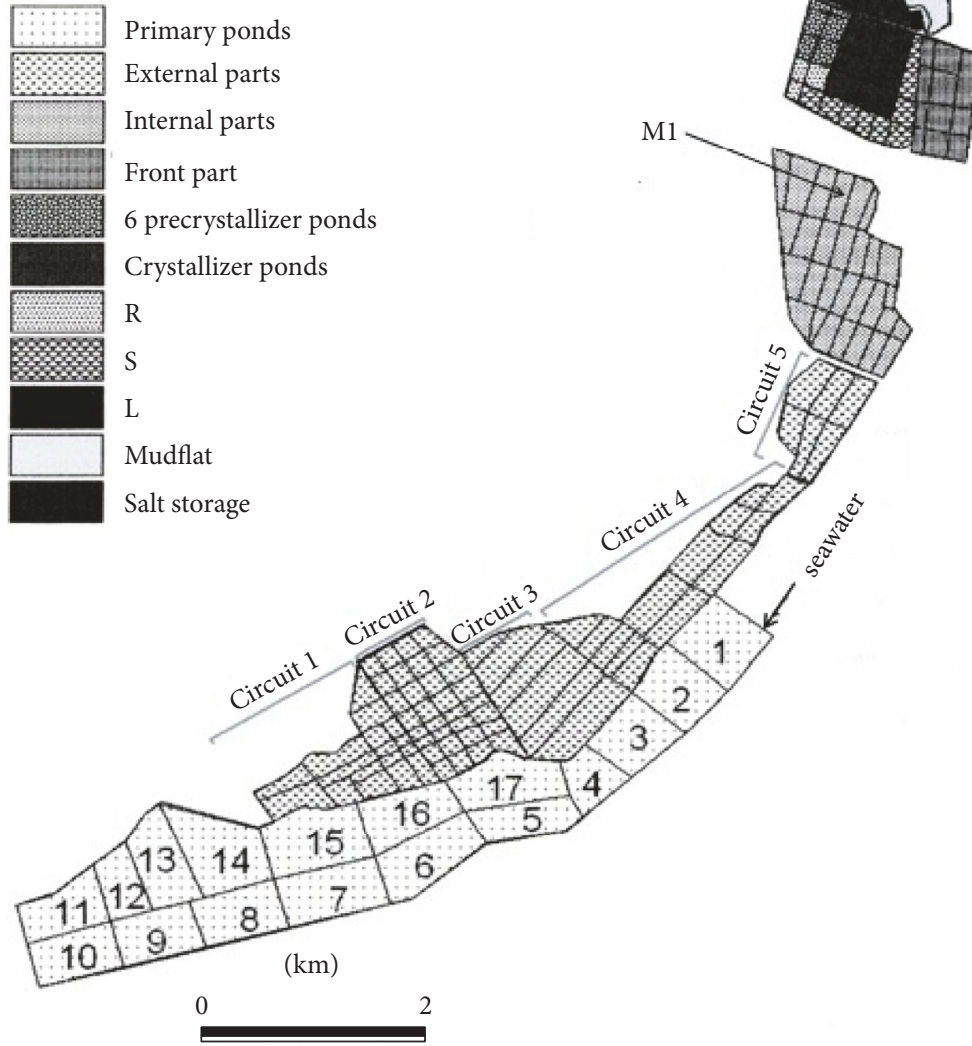

FIGURE 1: Map of the location of the two sampling ponds (TS18 and M1) of the Sfax solar saltern.

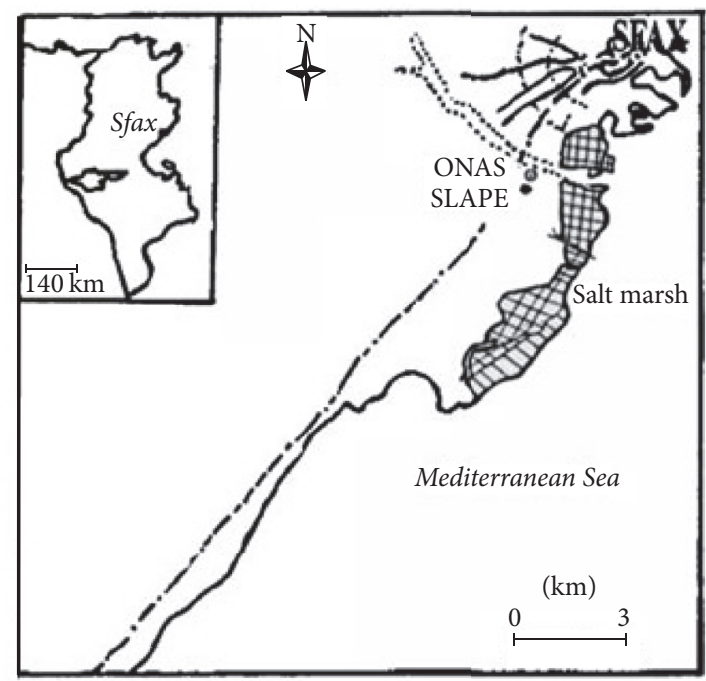

medium), and I (for ISP2 medium). The final number refers to the number of the isolates.

2.3. In Vitro Antimicrobial Activity. In order to study the antagonistic interaction between environmental actinomycetes, the isolates were grown on Bennett agar plates $(10 \% \mathrm{NaCl})$ for 21 days at $37^{\circ} \mathrm{C}$. Agar cylinders ( $6 \mathrm{~mm}$ in diameter) were then taken with hollow punch and deposited on the surface of the Bennett agar plate which had previously been seeded with one $\mathrm{ml}$ of 4-day cultured target-actinomycete strain. Plates were kept at $4^{\circ} \mathrm{C}$ for $2 \mathrm{~h}$ and then incubated at $37^{\circ} \mathrm{C}$ for $7-14$ days. The inhibition zones were measured after incubation and expressed in $\mathrm{mm}$.

The antimicrobial activities of the isolates were also tested against Gram - (Escherichia coli BW25113, Agrobacterium tumefaciens, Salmonella enterica ATCC43972, and Pseudomonas aeruginosa ATCC49189) and Gram+ (Micrococcus luteus LB 14110, Staphylococcus aureus ATCC6538, and Listeria ivanovii BUG 496) bacterial pathogens. The search for antibacterial activity was carried out by the method of disc agar [26], where actinomycete isolates were grown on Bennett agar medium for 14 days at $37^{\circ} \mathrm{C}$ and agar cylinders $(6 \mathrm{~mm}$ in diameter) were then taken and deposited on the surface of the Mueller-Hinton agar plates previously seeded with the test microorganism $\left(10^{5}-10^{6} \mathrm{CFU} / \mathrm{mL}\right)$. The inhibition zones were measured after 24 hours of incubation at $37^{\circ} \mathrm{C}$ and expressed in $\mathrm{mm}$.

2.4. Phenotypic and Growth Characteristics of Potential Isolates. Morphological, biochemical, culture, and physiological characterization of potential isolates were determined. Formation of aerial, substrate mycelium and spore arrangements on mycelium were observed with a light microscope (Reichert-Jung series 150 model) and monitored under a phase contrast microscope (Nikon ECLIPSE E600, USA) at 100x magnification. Various colony characteristics such as mycelia color, size, shape, and diffusible pigment production were recorded. Biochemical characterization, namely, Gram reaction, oxidase, catalase, and $\mathrm{H}_{2} \mathrm{~S}$, and indole production; urease, nitrate, and nitrite reduction; Red Methyl-Voges Prauskuer reactions; ONPG, citrate, and mannitol utilization were also performed as suggested by Holt et al. [27]. $\mathrm{NaCl}$ range tolerance and optimal requirement for growth were determined using Bennett medium agar supplemented with different concentrations of $\mathrm{NaCl}(0,5,10,15,20,25$, and $30 \%)$. 
Temperature and $\mathrm{pH}$ range for growth were also determined using Bennett medium [28].

\subsection{DNA Extraction of Potential Isolates and PCR Amplifica-} tion of $16 S$ rRNA. The six potential isolates were grown for 4 days at $37^{\circ} \mathrm{C}$ with agitation in $15 \mathrm{ml}$ of Bennett medium. Biomass was harvested by centrifugation at 4,000 rpm for $15 \mathrm{~min}$ and washed twice with sterile saline water. The method of Rainey et al. [29] was used for the extraction and purification of genomic DNA. The $16 \mathrm{~S}$ rDNA gene of the six isolates was amplified by polymerase chain reaction (PCR) using primers fD1 (5'AGAGTT TGATCCTG GCTCAG $3^{\prime}$ ) and Rs16 (5'AAG GAG GTG ATC CAA GCC $3^{\prime}$ ) [30]. The final volume of the reaction mixture of $50 \mu \mathrm{l}$ contained tampon buffer (10x) with $50 \mathrm{mM} \mathrm{MgCl}_{2}$, deoxynucleoside triphosphates (10 mM dNTP), $10 \mu \mathrm{M}$ (each) S1 and S2 primers, $2 \mu \mathrm{L}$ (80 ng) DNA, and $0.1 \mu \mathrm{L}$ Taq DNA polymerase $(5 \mathrm{U} / \mu \mathrm{L})$. Amplification was made using a Basic PCR protocol which consisted of an initial denaturation at $95^{\circ} \mathrm{C}$ for $10 \mathrm{~min}$, followed by 30 amplification cycles of $94^{\circ} \mathrm{C}$ for $45 \mathrm{~s}, 52^{\circ} \mathrm{C}$ for $30 \mathrm{~s}$, and $72^{\circ} \mathrm{C}$ for $1 \mathrm{~min}$ and $30 \mathrm{~s}$ and a final extension step of $72^{\circ} \mathrm{C}$ for $10 \mathrm{~min}$ [31]. The amplification result was detected by agarose gel (1\%) electrophoresis and visualized by ultraviolet fluorescence after ethidium bromide staining [32]. The purification of DNA 16S fragment from PCR on agarose gels was performed using the PureLink Quick Gel Extraction and PCR Purification Combo Kit. The same primers were then used separately in two sequencing reactions from the two ends of the amplified fragment (about $1.5 \mathrm{kbp}$ ). The two sequences obtained were compared for similarity with those contained in genomic database banks, using the NCBI BLAST [33].

2.6. Phylogenetic Analysis. Sequence data were established with the BioEdit program (http://www.mbio.ncsu.edu/ BioEdit/bioedit.html) and studied for sequence homology with the archived $16 \mathrm{~S}$ rDNA sequences from GenBank at https://www.ncbi.nlm.nih.gov/nucleotide, using the BLAST search program [34]. Different sequences were aligned with CLUSTAL W $[35,36]$ and a phylogenetic tree was constructed using the neighbor-joining DNA distance algorithm within the MEGA6 (Molecular Evolutionary Genetics Analysis Version 6.0) (http://www.megasoftware.net/) software [37]. The 16S rRNA gene sequences of the six potential thermoactinomycete strains have been deposited in the GenBank database under the accession numbers of KP229518KP229523.

\subsection{Production, Extraction, and Liquid Chromatography-High} Resolution Mass Spectrometry Analysis of Antimicrobial Products from Paludifilum halophilum. Paludifilum halophilum strain SMBg3 was cultured on Bennett medium supplemented with $10 \% \mathrm{NaCl}$, for 7 days at $37^{\circ} \mathrm{C}$. Mycelium was scraped and inoculated into four Erlenmeyer flasks (1L) containing $250 \mathrm{~mL}$ of the same medium. After seven days of incubation, the total broth was mixed, centrifuged at $4000 \mathrm{~g}$ for $15 \mathrm{~min}$, and then filtered through Whatman number 1 filter paper. The pellet was transferred aseptically into a conical flask and an equal volume of ethyl acetate was added to the filtrate and shaken vigorously for 2 hours for the complete extraction of the antibacterial compounds. The ethyl acetate phase containing the active principal was separated from the aqueous phase and was evaporated to a residue using Rota vapor (Heidolph: P/N Hei-VAP Value/G3: 560-01300-00). One mg of the residue was accurately weighed and dissolved in $300 \mu \mathrm{L}$ of ethyl acetate and this solution was filtered through $0.2 \mu \mathrm{m}$ PTFE filter into HPLC vial where it is submitted to LC/MS analysis. High resolution mass spectrometric data were obtained using a ThermoLTQOrbitrap coupled to an HPLC system (PDA detector, PDA autosampler, and pump). The following conditions were used: capillary voltage of $45 \mathrm{~V}$, capillary temperature of $260^{\circ} \mathrm{C}$, auxiliary gas flow rate of 10-20 arbitrary units, sheath gas flow rate of 40-50 arbitrary units, spray voltage of $4.5 \mathrm{kV}$, and mass range of 100-2000 amu (maximal resolution of 30000). For LC/MS, a Sunfire C18 analytical HPLC column ( $5 \mu \mathrm{m}, 4.6 \mathrm{~mm}$ $\times 150 \mathrm{~mm}$ ) was used with a mobile phase of 0 to $100 \% \mathrm{MeOH}$ over $30 \mathrm{~min}$ at a flow rate of $1 \mathrm{~mL} / \mathrm{min}$.

\section{Results and Discussion}

3.1. Physicochemical and Microbiological Analysis of Samples. The physicochemical parameters of the water above the sediment surface and the microbiological parameters of the water and superficial sediment from which cores were collected during the three campaigns are summarized in Table 1. M1 pond was characterized by an intermediate salinity ranging from 19 to $21 \%$, whereas the TS18 pond had a higher salinity that varied between 31 and 36\%. Temperature was slightly higher in pond TS18 than in M1, while pH was slightly alkaline in M1 and close to neutrality in TS. Moreover, dissolved organic carbon was found to be significantly higher in TS18 than in M1. It was noticed that superficial sediment samples from M1 contained gypsum deposit, while those of TS were constituted with halite. The maximum values of total cell counts $\left(5.9 \times 10^{9}\right.$ cells $\left./ g\right)$ were detected in the sediment of the TS18 pond and were 2-3-fold higher than in M1 pond (Table 1). In addition, when comparing water and sediment samples, it was found that, for both prospected ponds, the maximum values of total cell counts were detected in sediments and were 3- to 10-fold higher than those obtained in waters (Table 1). This could be attributed to greater organic matter abundance [38] and lower predation rates $[19,39]$.

The cultivable actinomycete density during the 3 sampling campaigns showed different patterns in M1 and TS18 ponds, with counts between 2.5 and 7 times higher in TS18 than in M1 (Table 1). Intriguingly, for both M1 and TS18, no cultivable actinomycetes could be detected in waters, while their counts in superficial sediments were much lower than those reported in previous studies [40, 41].This could be explained, in part, by the high salinity of the prospected ponds and the severe selective pressure of our isolation procedure, which allows the growth of only halophilic strains able to support at least a salinity of $15 \%$. In fact, the occurrence of actinomycetes in the hypersaline environment has been reported in several previous studies, stating the decrease in actinomycetes colonies forming units counts with 
TABLE 1: Range of physicochemical characteristics of water above the two ponds' sediment surface and microbiological parameters during the three campaigns.

\begin{tabular}{|c|c|c|}
\hline Parameters & Pond M1 & Pond TS18 \\
\hline \multicolumn{3}{|l|}{ Physicochemical } \\
\hline $\mathrm{pH}$ & $8.3-8.5 \pm 0.1$ & $7.2-7.8 \pm 0.2$ \\
\hline Salinity (\%) & $19-21 \pm 1$ & $31-36 \pm 1$ \\
\hline Temperature $\left({ }^{\circ} \mathrm{C}\right)$ & $14-19 \pm 1$ & $16-22 \pm 1$ \\
\hline Dissolved organic carbon $\left(\mathrm{mg} \mathrm{l}^{-1}\right)$ & $2.7-3.1 \pm 0.5$ & $5.8-7.4 \pm 0.5$ \\
\hline \multicolumn{3}{|l|}{ Microbiological } \\
\hline Water total cell count $\left(10^{8}\right.$ cells $\left.\mathrm{ml}^{-1}\right)$ & $1.2-1.8 \pm 0.01$ & $3.2-19 \pm 0.05$ \\
\hline Sediment total cell count $\left(10^{8}\right.$ cells $\left.\mathrm{g}^{-1}\right)$ & $13-19 \pm 0.02$ & $36-59 \pm 0.1$ \\
\hline Water cultivable actinomycete count (UFC $\left.\mathrm{ml}^{-1}\right)$ & 0 & $0-1$ \\
\hline Sediment cultivable actinomycete count $\left(\mathrm{UFC}^{-1}\right)$ & $3-30 \pm 1$ & $20-70 \pm 3$ \\
\hline Number of actinomycete isolates from water & 0 & 0 \\
\hline Number of actinomycete isolates from sediment & 3 & 20 \\
\hline
\end{tabular}

Each data is mean of three independent analyses \pm standard deviation; $P$ value $<0.05$.

the increase in salinity [41, 42]. In addition, the ability of actinomycete cells to enter a viable but nonculturable state in response to stressful conditions, in which bacteria lost their ability to form colonies in the surface of solid media, could not be discarded $[43,44]$.

\subsection{Isolation of Strains and Screening of Antimicrobial Activ-} ities. Given that less than $1 \%$ of bacteria from saline environments can be cultured, the use of appropriate isolation media is critical for improving the recovery of Actinobacteria [45]. Six isolation media were chosen in this study to select for Actinobacteria. During the 3 sampling campaigns and based on colony morphology, growth characteristics, and macroscopic examination, a total of twenty-three actinomycete strains were collected on all isolation media with 3 being isolated from M1 and 20 from TS18 (Table 1). Bennett medium exhibited the highest recovery producing 9 isolates, followed by GTY medium with 7 strains while no strain was recovered on ISP2 medium. Most isolates showed, on Bennett medium at $10 \% \mathrm{NaCl}$, aerial mycelia with color varied from yellow and light yellow to beige white and fluorescent spores arranged in chains.

The 23 strains were tested for their ability to produce antimicrobial substances. The result of antagonistic interactions between the actinomycete strains, taken in pairs, allowed the detection of 18 active strains named STS3, STB1, STG6, STG1, STC3, STS2, STC4, STG4, STB7, SMC3, SMBg3, STG8, STC5, STG2, STB6, STB8, STB2, and STG5 producing antimicrobial compounds against one or more targetactinomycete strains (Table 2). The halo diameter was used to monitor each strain level of antimicrobial substance produced. Our results showed that the inhibition zones diameter versus the target strain ranged from 13 to $33 \mathrm{~mm}$ and their activity spectrum comprised between one and 8 target strains, which suggested that the produced substances could be of a different nature (Table 2). Most strains (thirteen of the eighteen) have a wide spectrum of inhibition, with at least two sensitive strains (Table 2).
The isolates antibacterial potential was also analyzed against seven pathogen strains and the antibacterial activity extent was varied among the actinobacterial isolates (Table 3). Nineteen out of the 23 strains of halophilic actinomycetes exhibited appreciable inhibitory activity against Gram-negative and/or Gram-positive bacteria. Among them, 5 strains, named STB2, STC3, STG2, SMB5, and SMC3, acted only against Gram-negative bacteria and 6 strains (STG3, STG4, STG6, STB1, STB3, and STB4) against only Grampositive bacteria. The 8 remaining strains (STB6, STB8, STS2, STS3, STC5, STC4, STG1, and SMBg3) revealed excellent antibacterial activity against both Gram-positive and Gram-negative bacteria. Interestingly, when the antagonistic activity was lacking for one strain, either it was completely inactive on human pathogens or its activity was strongly reduced. In the literature, while the antagonistic properties of halotolerant and moderate halophilic actinomycetes have often been reported in the literature at low or medium salinity [41, 46, 47], those of halophilic isolates at salinity close to saturation have never been mentioned. This is the first report showing that the crystallizer and noncrystallizer ponds of Sfax marine saltern harbored potential halophilic actinomycetes producing antimicrobial compounds against Gram-positive and Gram-negative pathogen bacteria. Based on their broad (STB8, STS2, STS3, STC4, and SMBg3) or narrow (SMC3) activity spectrum, 6 strains among all the actinomycete isolated were, therefore, subjected to detailed taxonomic studies.

3.3. Characterization of Potential Isolates. In order to estimate the relatedness between the 6 potent isolates, the physiological, biochemical, and growth characteristics of each strain were compared. Results in Table 4 revealed that the colonies of the six isolates were circular and aerial mycelium was observed for only STC4, SMC3, STB8, and SMBg3 with fluorescent spores arranged in chains. However, substrate mycelium was between pale yellow for SMBg3 and SMC3, white for STS3 and STS2, colorless for STC4, and transparent 


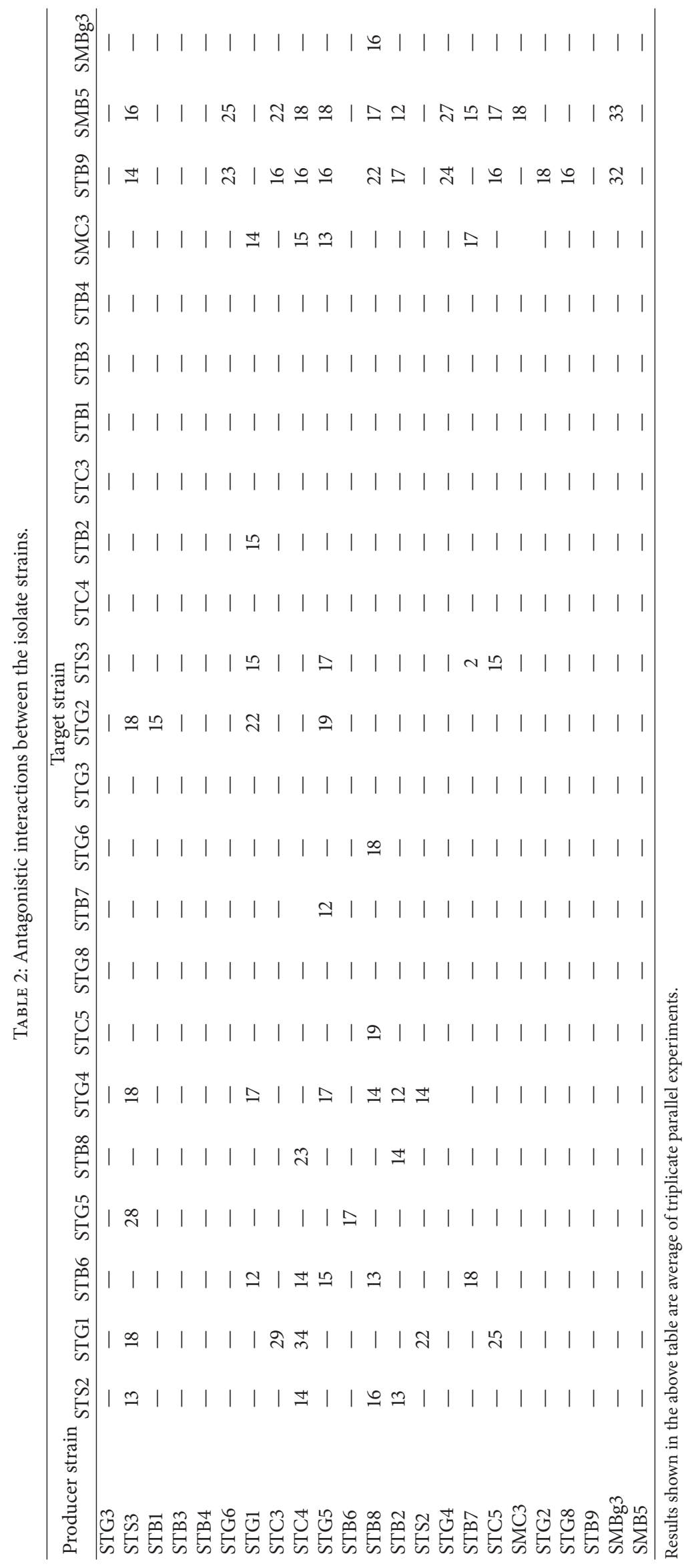


TABLE 3: Antimicrobial activities of halophilic actinomycetes isolated from solar salterns of Sfax.

\begin{tabular}{|c|c|c|c|c|c|c|c|}
\hline Strains & A. tumefaciens & S. aureus & S. enterica & M. luteus & E. coli & L. ivanovii & P. aeruginosa \\
\hline STB2 & - & - & - & - & 12 & - & 15 \\
\hline STB6 & - & - & 14 & - & 17 & 13 & 16 \\
\hline STB8 & 12 & 11 & 16 & - & 14 & - & 21 \\
\hline STG5 & - & - & - & - & - & - & - \\
\hline STS2 & 14 & - & 12 & 12 & 16 & 14 & - \\
\hline STS3 & 15 & 12 & 14 & - & 17 & - & - \\
\hline STC4 & 12 & 14 & 14 & 14 & 14 & - & - \\
\hline STC5 & - & - & - & - & 15 & 12 & - \\
\hline STC3 & - & - & - & - & 13 & - & 19 \\
\hline STG3 & - & - & - & - & - & 11 & - \\
\hline STG4 & - & 23 & - & - & - & 12 & - \\
\hline STG6 & 14 & - & - & - & - & 13 & - \\
\hline STB1 & - & - & - & - & - & 11 & - \\
\hline STB3 & - & - & - & - & - & 11 & - \\
\hline STB4 & - & - & - & - & - & 11 & - \\
\hline STG8 & - & - & - & - & - & - & - \\
\hline STG1 & 15 & - & - & 12 & 15 & - & - \\
\hline STB7 & - & - & - & - & - & - & - \\
\hline STG2 & - & - & 16 & - & 15 & - & - \\
\hline STB9 & - & - & - & - & - & - & - \\
\hline SMBg3 & 15 & 15 & 16 & - & 15 & - & 16 \\
\hline SMB5 & - & - & - & - & 20 & - & - \\
\hline SMC3 & - & - & - & - & 13 & - & - \\
\hline
\end{tabular}

Results shown in the above table are average of triplicate parallel experiments.

for STB8. Gram and catalase reactions were positive for all strains. All the isolates could not metabolize mannitol and ONPG or produce $\mathrm{H}_{2}$ S. Only STC4 and STB8 strains were nitrate reductase + , while RM and VP reactions were negative for all isolates, except STB8 which was RM positive. Isolates were also screened for their growth at various $\mathrm{NaCl}$, temperature, and $\mathrm{pH}$ levels. All isolates exhibited growth in the $\mathrm{NaCl}$ range of $5-20 \%$ with an optimum at $10 \% \mathrm{NaCl}$ and at a temperature range of $30-55^{\circ} \mathrm{C}$ with an optimum of $45^{\circ} \mathrm{C}$, while $\mathrm{pH}$ range for growth was between 5.0 and 11.0 with an optimum at 8.0-8.5 for all strains. These results showed that all isolates in this study were halophilic and thermotolerant. Carbon source utilization is also given in Table 4, showing that the six strains could metabolize glucose and starch, but not sucrose. However, saccharose, maltose, and xylose were metabolized weakly by STS2 strain and strongly by the others. Our results showed also that the actinomycete strains constitute potential producers of amylase ( $69 \%$ of the total isolates), followed by protease (52\%), cellulase, DNase (39\%), and lipase (4\%). This is in agreement with our previous studies conducted on the same ponds which found that the most frequent hydrolytic activity among archaeal isolates was observed for amylase and protease [21]. Assuming that these frequencies are related to the nature of the organic matter in the pond, these results may suggest that carbohydrates and proteins in the sediment are the major carbon sources for the halophilic prokaryotes inhabiting the two ponds [19].

To ascertain the phylogenetic relationships of potential strains, their almost-complete 16S rRNA gene sequences (1352-1483 bp) were determined. A comparative sequence analysis using the BLAST program and a phylogenetic analysis using neighbor-joining revealed that the six strains were very close and formed a distinct sublime within the Thermoactinomycetaceae family (Figure 2). The six strains shared the highest 16S rRNA sequence similarity with respect to the strain types of Salinithrix halophila CECT $8506^{\mathrm{T}}$ (94\%), Desmospora activa DSM $45169^{\mathrm{T}}(94 \%)$, Kroppenstedtia guangzhouensis KCTC $29149^{\mathrm{T}}$ (95\%), Kroppenstedtia eburnea DSM $45196^{\mathrm{T}}$ (95\%), and Melghirimyces algeriensis (95\%). These similarity percentages lower than $97 \%$ suggested that the isolated actinomycete strains could represent new members of the Thermoactinomycetaceae family and their sequences were published in the GenBank database under the accession numbers of KP229518-KP229523. To go further in the taxonomic position of these strains in the phylum Actinobacteria, we recently performed a polyphasic taxonomic study on strain SMBg3 [16]. Our results revealed that this strain occupied an independent phylogenetic lineage distinct from all other reference genera within the family Thermoactinomycetaceae. On the basis of these data and 


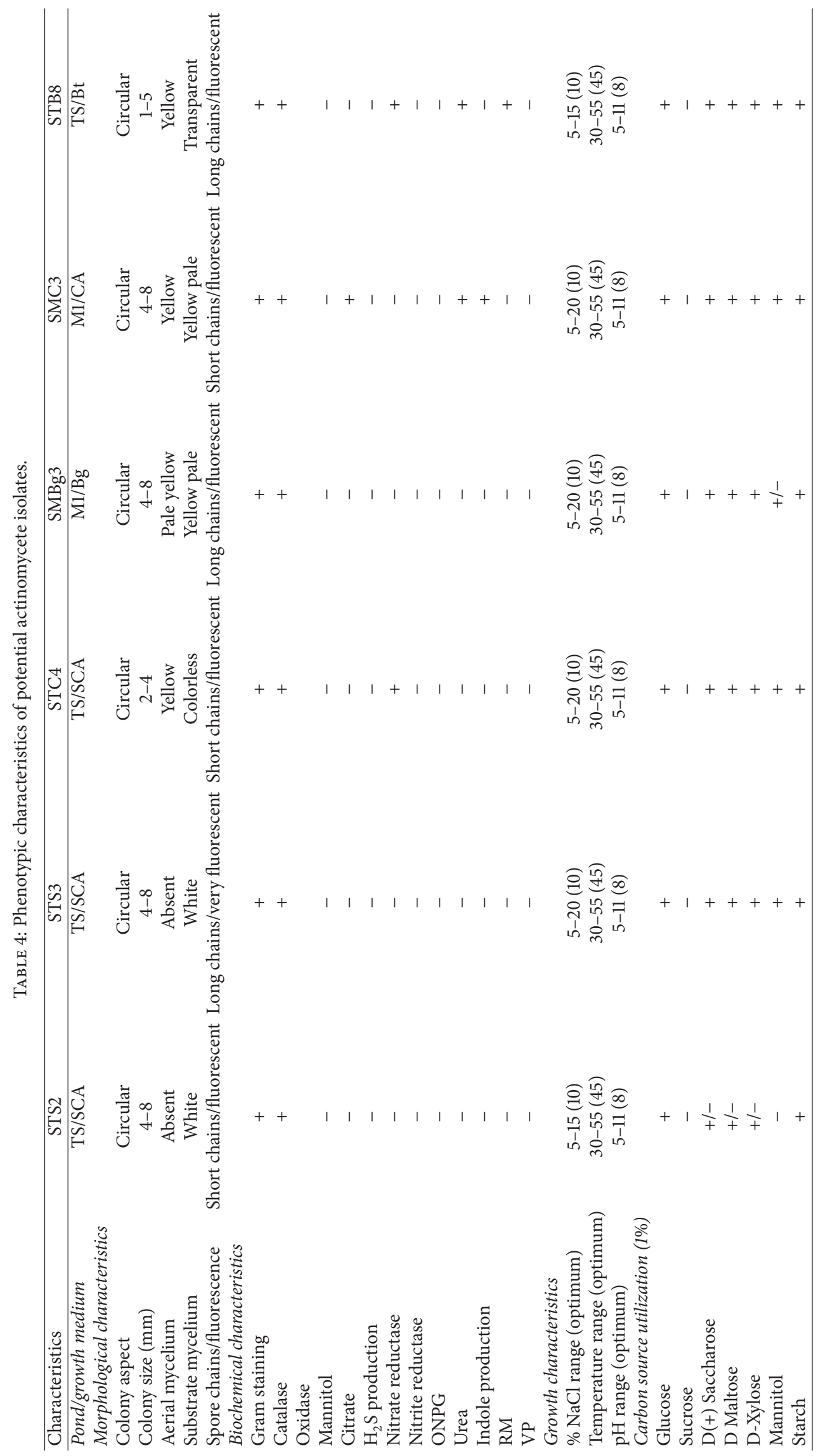




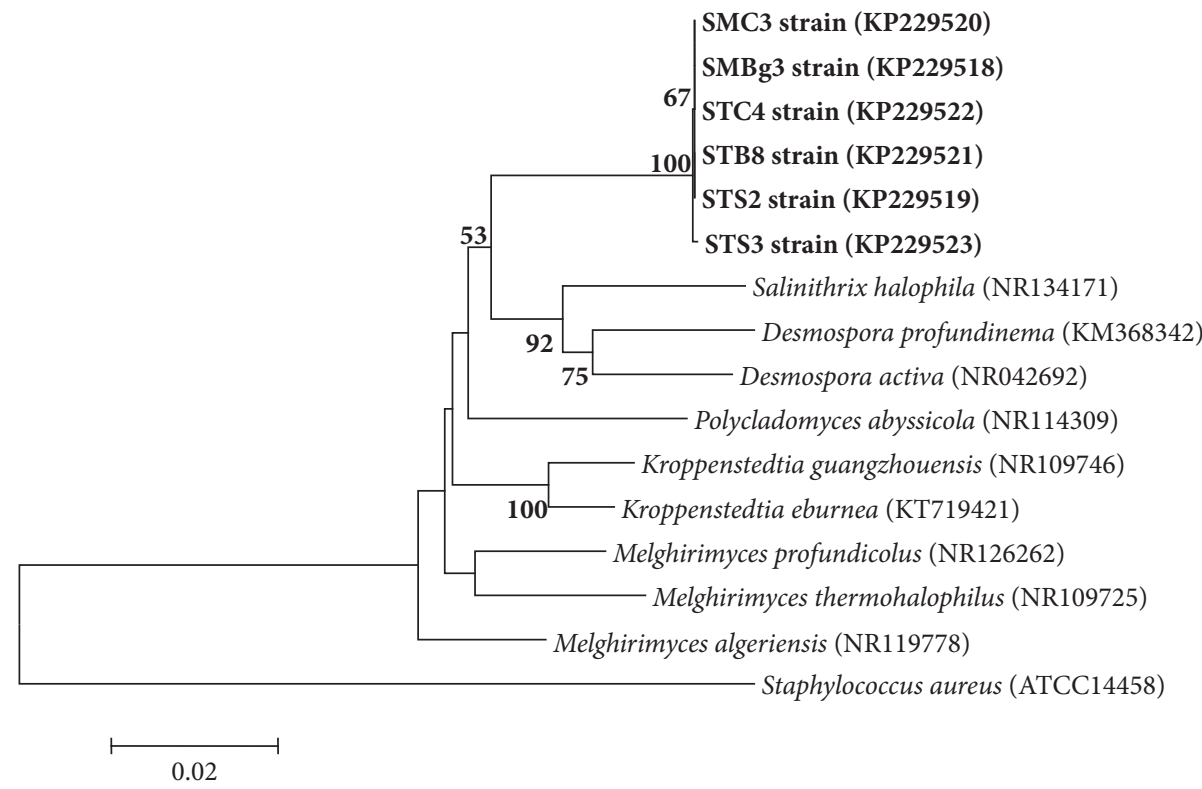

FIGURE 2: Neighbor-joining tree based on 16S rDNA sequences showing the relations between the halophilic actinomycete strains (STS2, STC4, STB8, SMBg3, STC3, and STS3) and type species of the family Thermoactinomycetaceae. The accession numbers of strain sequences are given in parentheses. The numbers at the nodes indicate the levels of bootstrap support based on neighbor-joining analyses of 1000 resampled datasets; only values over $50 \%$ are given. Bar: 0.02 nucleotide substitutions per nucleotide position. Staphylococcus aureus (ATCC14458) is given as outgroup.

other phenotypic and chemotaxonomic characteristics, strain SMBg3 was assigned to a new genus in the family Thermoactinomycetaceae for which the name Paludifilum was proposed and the type strain of the type species $\mathrm{SMBg}^{\mathrm{T}}$ was named Paludifilum halophilum and deposited in the $\operatorname{DSMZ}\left(=\mathrm{DSM} 102817^{\mathrm{T}}\right)$ and CCUG $\left(=\mathrm{CCUG} 68698^{\mathrm{T}}\right)$ public collections [16]. In fact, the occurrence of new genera of halophilic thermoactinomycetes has been reported in the hypersaline environments of distant geographical sites such as the Algerian salt lake [17] and the soil of hypersaline wetland in the north of Iran [18]. The saltern of Sfax can thus be considered as an additional geographical site harboring new members of halophilic thermoactinomycetes. Moreover, this is the first report revealing that these microbes could have an antimicrobial potential.

3.4. Production, Purification, and LC/MS Characterization of Antimicrobial Compounds Produced by Paludifilum halophilum. In order to unveil the preliminary characteristics of antimicrobial compounds produced by Paludifilum halophilum strain $\mathrm{SMBg3}$, the strain was cultivated in large scale and active substances were extracted by ethyl acetate as mentioned above and tested against three Gram-positive and four Gram-negative bacteria at a $2.5 \mathrm{mg} /$ disc concentration. Our results showed good activity against $S$. aureus ATCC6538 (14 mm), E. coli W 25113 (15 mm), A. tumefaciens (14 mm), S. enterica ATCC43972 (16 mm), and P. aeruginosa ATCC49189 $(16 \mathrm{~mm})$. No inhibition was observed for $M$. luteus and L. ivanovii. In a previous study by Vijayakumar et al. [48], the ethyl acetate extract of Streptomyces sp. was highly active against Vibrio cholerae $(26 \mathrm{~mm})$, Salmonella typhi $(24 \mathrm{~mm})$, Proteus vulgaris $(23 \mathrm{~mm})$, Candida albicans $(17 \mathrm{~mm})$, Klebsiella pneumoniae $(16 \mathrm{~mm})$, Proteus mirabilis (15 mm), Staphylococcus aureus $(15 \mathrm{~mm})$, and Escherichia coli $(14 \mathrm{~mm})$. In Tunisia, little attention has been paid to the antimicrobial activity of actinomycetes. To date, only one study has been conducted by Trabelsi et al. [49] on different rhizospheric soils and showed that, among fifty-four isolates of actinomycetes collected, 42 strains were classified as Streptomyces, 4 strains were classified as Micromonospora, 1 was classified strain as Pseudonocardia, 1 strain was classified as Actinomadura, 1 was classified strain as Nocardia, and 5 strains were classified as non-Streptomyces. In addition, more than the half of the ethyl acetate extract of these isolates was shown to inhibit at least one tested pathogenic microorganisms in liquid culture.

The LC-MS profiles of the crude extract of Paludifilum halophilum strain SMBg3 are shown in Figure 3. The chromatograph showed five major constituents whose structures are provided in Table 5. Molecular formula and chemical structures of these compounds were deduced from the quasimolecular ion peak $[\mathrm{M}+\mathrm{H}]^{+}$on the basis of their HRESI-MS spectrum. These five major constituents are the cyclic lipopeptide Gramicidin S (Rt: $9.08 \mathrm{~min}$ ) and four cyclic dipeptides (CDPs) identified as cyclo(L-4-OH-Pro-L-Leu) (Rt: $4.08 \mathrm{~min}$ ), cyclo(L-Tyr-L-Pro) (Rt: $4.83 \mathrm{~min}$ ), cyclo(LPhe-L-Pro) (Rt: $5.18 \mathrm{~min}$ ), and cyclo(L-Leu-L-Pro) (Rt: $5.87 \mathrm{~min}$ ). In fact, CDPs [also known as 2,5-dioxopiperazines; 2,5-diketopiperazines; cyclo(dipeptides); or dipeptide anhydrides] are well known for their economically beneficial 
TABLE 5: LC-HR-ESI-MS analysis of the most interesting compounds extracted from liquid cultures of Paludifilum halophilum strain SMBg3.

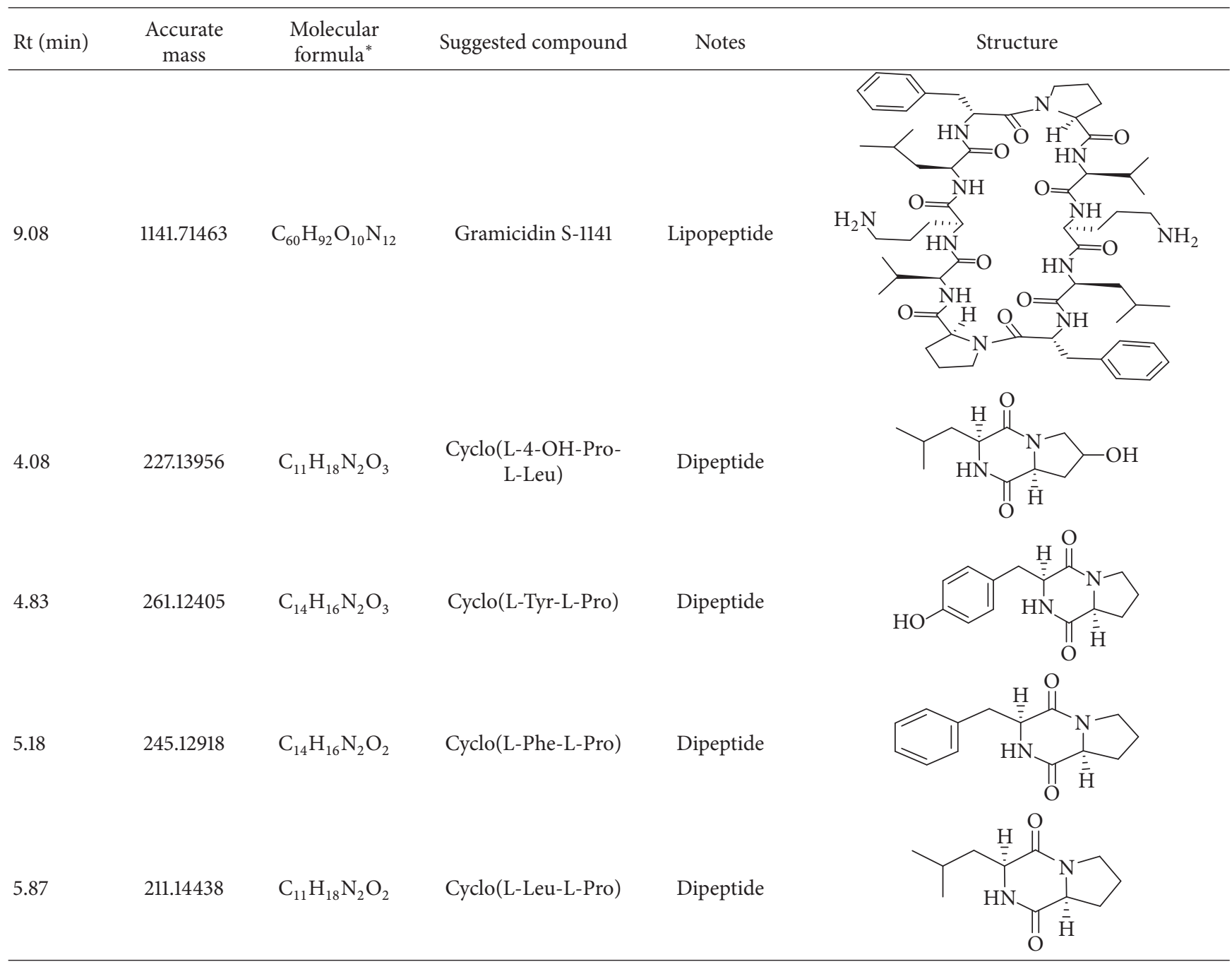

${ }^{*}$ Formula deduced from the quasimolecular ion peak $[\mathrm{M}+\mathrm{H}]^{+}$.

biological activities and therefore are among the most common peptide derivatives found in nature [50]. They have been isolated from microorganisms, sponges, and from a variety of tissues and body fluids [51-53]. The cyclic form of the dipeptide is often more stable in vivo than its linear counterpart, making them far more promising in terms of drug candidacy [54]. Both natural and synthetic diketopiperazines have a wide variety of biological activities, including antitumor [55] (Nicholson et al. 2006), antiviral [56], antifungal [57], and antibacterial [58] activities. For instance, the cyclo(Pro-Tyr) was first isolated from Alternaria alternate [53] and then from Streptomyces sp. TN25644. Cain et al. [59] reported that cyclo(Pro-Tyr) exhibits no activity against strains of Micrococcus luteus, Mycobacterium smegmatis, Sacharomyces cerevisiae, Candida neoformans, Candida albicans, and Aspergillus niger. In contrast, Smaoui et al. [60] reported a strong antimicrobial activity of cyclo(Pro-Tyr) against Micrococcus luteus LB 14110, Salmonella enterica ATCC43972, and Fusarium sp.

\section{Conclusions}

This study deals with the isolation, characterization, and antimicrobial potentiality of a collection of halophilic actinomycete strains isolated from the solar saltern of Sfax. Our results revealed, for the first time, that the superficial sediment of this ecosystem is a source of novel halophilic actinomycetes belonging to the Thermoactinomycetaceae family with unexplored potential for antimicrobial discovery. For the potent strain SMBg3, assigned to a new genus in the family and named Paludifilum halophilum, we have shown that the observed antimicrobial activity is most likely explained by the production of Gramicidin $\mathrm{S}$ and four cyclic dipeptides identified as cyclo(L-4-OH-Pro-LLeu), cyclo(L-Tyr-L-Pro), cyclo(L-Phe-L-Pro), and cyclo(LLeu-L-Pro). The potent inhibitory effect of these compounds covered the growth of the plant pathogen A. tumefaciens and the human pathogens $S$. aureus, S. enterica, E. coli, and P. aeruginosa. To the best of our knowledge, this is the first time that the bioactivity of cyclic antimicrobial peptides 


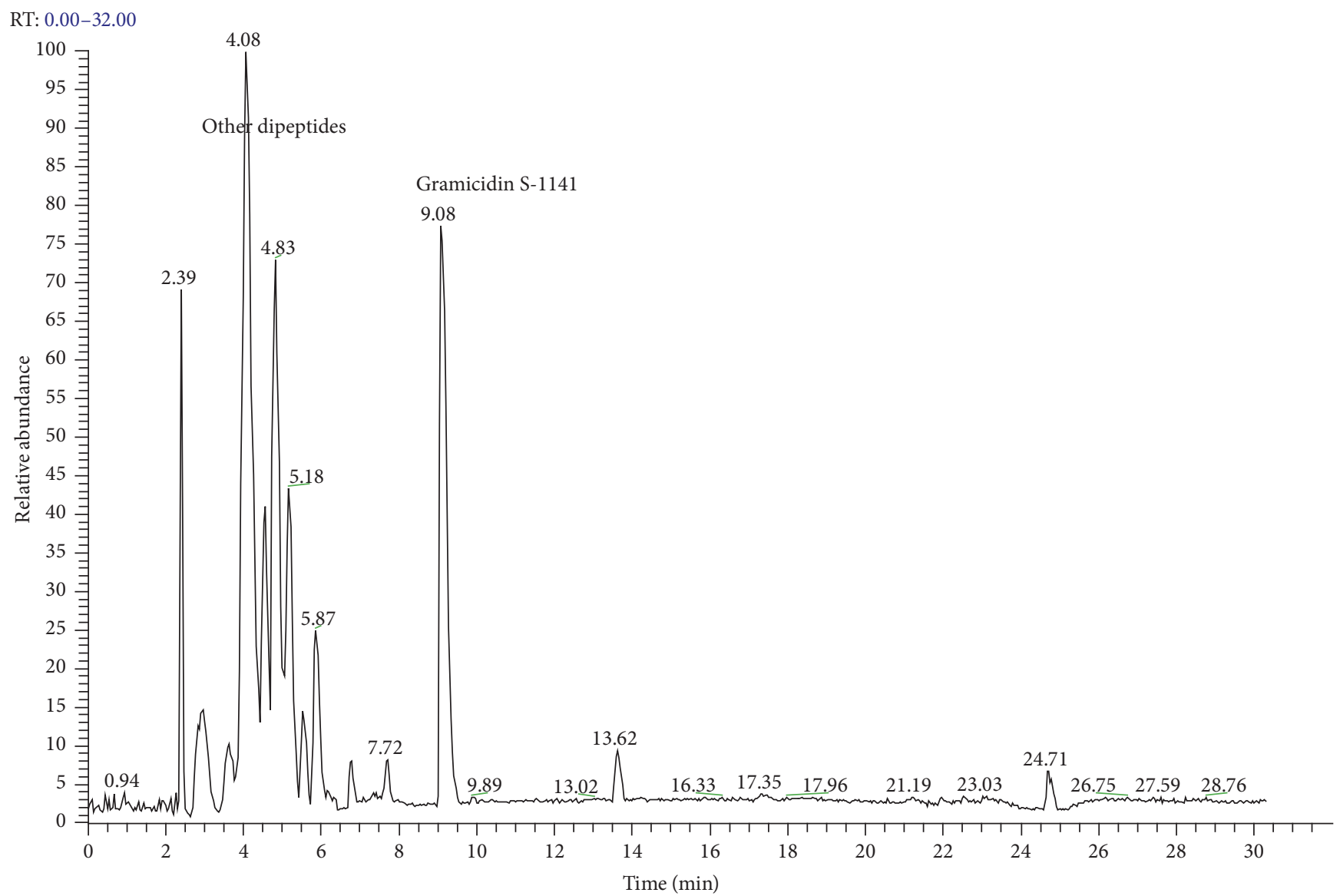

FIGURE 3: LC/MS chromatogram of the crude extract from Paludifilum halophilum strain SMBg3.

from halophilic thermoactinomycete against agriculturally and medically important bacteria is reported. Our work is now in progress to purify these cyclic antimicrobial peptides for further characterization.

\section{Conflicts of Interest}

The authors declare no conflicts of interest.

\section{Acknowledgments}

The authors are grateful to Dr. Ridha Amdouni from COTUSAL salt company for allowing members of their research team access to the saltern and Dr. Hafeth Bjaoui from the English Language Unit at the Faculty of Science of Sfax, Tunisia, for careful proofreading.

\section{References}

[1] J. D. Walker and R. R. Colwell, "Factors affecting enumeration and isolation of actinomycetes from Chesapeake Bay and Southeastern Atlantic Ocean sediments," Marine Biology, vol. 30, no. 3, pp. 193-201, 1975.

[2] J. A. Colquhoun, J. Mexson, M. Goodfellow, A. C. Ward, K. Horikoshi, and A. T. Bull, "Novel rhodococci and other mycolate actinomycetes from the deep sea," Antonie van Leeuwenhoek, International Journal of General and Molecular Microbiology, vol. 74, no. 1-3, pp. 27-40, 1998.
[3] H. S. Chaudhary, B. Soni, A. R. Shrivastava, and S. Shrivastava, "Diversity and versatility of actinomycetes and its role in antibiotic production," Journal of Applied Pharmaceutical Science, vol. 3, no. 8, pp. S83-S94, 2013.

[4] J. Hamedi, F. Mohammadipanah, and A. Ventosa, "Systematic and biotechnological aspects of halophilic and halotolerant actinomycetes," Extremophiles, vol. 17, no. 1, pp. 1-13, 2013.

[5] C. Jiang and L. Xu, "Actinomycete diversity in unusual habitats," Actinomycetes, vol. 4, pp. 47-57, 1993.

[6] C. Imada, N. Koseki, M. Kamata, T. Kobayashi, and N. HamadaSato, "Isolation and characterization of antibacterial substances produced by marine actinomycetes in the presence of seawater," Actinomycetologica, vol. 21, no. 1, pp. 27-31, 2007.

[7] V. V. Selyanin, G. E. Oborotov, G. M. Zenova, and D. G. Zvyagintsev, "Alkaliphilic soil actinomycetes," Microbiology, vol. 74, no. 6, pp. 729-734, 2005.

[8] A. Meklat, N. Sabaou, A. Zitouni, F. Mathieu, and A. Lebrihi, "Isolation, taxonomy, and antagonistic properties of halophilic actinomycetes in saharan soils of algeria," Applied and Environmental Microbiology, vol. 77, no. 18, pp. 6710-6714, 2011.

[9] P. Solanki and V. Kothari, "Halophilic actinomycetes: salt-loving filaments," International Journal of Life Science and Technology, vol. 4, pp. 7-13, 2011.

[10] P. A. Jose and S. R. D. Jebakumar, "Unexplored hypersaline habitats are sources of novel actinomycetes," Frontiers in Microbiology, vol. 5, article 242, pp. 1-3, 2014.

[11] P. Rajeswari, P. A. Jose, R. Amiya, and S. R. D. Jebakumar, "Characterization of saltern based Streptomyces sp. and statistical 
media optimization for its improved antibacterial activity," Frontiers in Microbiology, vol. 5, 2014.

[12] Y. Matsuo, A. Katsuta, S. Matsuda, Y. Shizuri, A. Yokota, and H. Kasai, "Mechercharimyces mesophilus gen. nov., sp. nov. and Mechercharimyces asporophorigenens sp. nov., antitumor substance-producing marine bacteria, and description of Thermoactinomycetaceae fam. nov," International Journal of Systematic and Evolutionary Microbiology, vol. 56, no. 12, pp. 2837-2842, 2006.

[13] J.-H. Yoon, I.-G. Kim, Y.-K. Shin, and Y.-H. Park, "Proposal of the genus Thermoactinomyces sensu stricto and three new genera, Laceyella, Thermoflavimicrobium and Seinonella, on the basis of phenotypic, phylogenetic and chemotaxonomic analyses," International Journal of Systematic and Evolutionary Microbiology, vol. 55, no. 1, pp. 395-400, 2005.

[14] K. Hatayama, H. Shoun, Y. Ueda, and A. Nakamura, "Planifilum fimeticola gen. nov., sp. nov. and Planifilum fulgidum sp. nov., novel members of the family 'Thermoactinomycetaceae' isolated from compost," International Journal of Systematic and Evolutionary Microbiology, vol. 55, no. 5, Article ID 63367, pp. 2101-2104, 2005.

[15] K. Hatayama and T. Kuno, "Croceifilum oryzae gen. Nov., sp. nov., isolated from rice paddy soil," International Journal of Systematic and Evolutionary Microbiology, vol. 65, no. 11, pp. 4061-4065, 2015.

[16] D. Frikha-Dammak, M. L. Fardeau, J. L. Cayol et al., "Paludifilum halophilum gen. nov., sp. nov., a thermoactinomycete isolated from superficial sediment of a solar saltern," International Journal of Systematic and Evolutionary Microbiology, vol. 66, pp. $1-8,2016$.

[17] A. N. Addou, P. Schumann, C. Spröer, H. Hacene, J.-L. Cayol, and M.-L. Fardeau, "Melghirimyces algeriensis gen. nov., sp. nov., a member of the family Thermoactinomycetaceae, isolated from a salt lake," International Journal of Systematic and Evolutionary Microbiology, vol. 62, no. 7, pp. 1491-1498, 2012.

[18] P. Zarparvar, M. A. Amoozegar, M. M. Nikou, P. Schumann, and A. Ventosa, "Salinithrix halophila gen. nov., sp. nov., a halophilic bacterium in the family Thermoactinomycetaceae," International Journal of Systematic and Evolutionary Microbiology, vol. 64, pp. 4115-4119, 2014.

[19] J. Elloumi, W. Guermazi, H. Ayadi, A. Bouain, and L. Aleya, "Abundance and biomass of prokaryotic and eukaryotic microorganisms coupled with environmental factors in an arid multi-pond solar saltern (Sfax, Tunisia)," Journal of the Marine Biological Association of the United Kingdom, vol. 89, no. 2, pp. 243-253, 2009.

[20] H. Trigui, S. Masmoudi, C. Brochier-Armanet et al., "Characterization of heterotrophic prokaryote subgroups in the Sfax coastal solar salterns by combining flow cytometry cell sorting and phylogenetic analysis," Extremophiles, vol. 15, no. 3, pp. 347358, 2011.

[21] D. F. Dammak, S. M. Smaoui, F. Ghanmi, I. Boujelben, and S. Maalej, "Characterization of halo-alkaline and thermostable protease from Halorubrum ezzemoulense strain ETR14 isolated from Sfax solar saltern in Tunisia," Journal of Basic Microbiology, vol. 56, no. 4, pp. 337-346, 2016.

[22] S.-K. Tang, X.-Y. Zhi, Y. Wang et al., "Haloactinobacterium album gen. nov., sp. nov., a halophilic actinobacterium, and proposal of Ruaniaceae fam. nov.," International Journal of Systematic and Evolutionary Microbiology, vol. 60, no. 9, pp. 2113-2119, 2010 .
[23] S. Ramesh and N. Mathivanan, "Screening of marine actinomycetes isolated from the Bay of Bengal, India for antimicrobial activity and industrial enzymes," World Journal of Microbiology and Biotechnology, vol. 25, no. 12, pp. 2103-2111, 2009.

[24] J. Chun, Kyung Sook Bae, Eun Young Moon, S.-O. Jung, Hong Kum Lee, and S.-J. Kim, "Nocardiopsis kunsanensis sp. nov., a moderately halophilic actinomycete isolated from a saltern," International Journal of Systematic and Evolutionary Microbiology, vol. 50, no. 5, pp. 1909-1913, 2000.

[25] L. Ben Fguira-Fourati, S. Bejar, and L. Mellouli, "Isolation and screening of Streptomyces from soil of Tunisian oases ecosystem for non polyenic antifungal metabolites," African Journal of Biotechnology, vol. 29, pp. 7512-7519, 2012.

[26] A. M. Tortorano, E. Cabrini, and M. A. Vivani, "Sensibilité in vitro des Levures à cinq antibiotiques. Comparaison de deux methodes C.M.I. en gelose et methode des disques," Bulletin of Social Frame Mycology and Medecine, vol. 8, pp. 69-74, 1979.

[27] J. G. Holt, N. R. Krieg, P. H. Sneath, J. T. Staley, and S. T. Williams, Bergey's Manual of Determinative Bacteriology, The Williams and Wilkins Company, Philadelphia, Pa, USA, 9th edition.

[28] E. B. Shirling and D. Gottileb, "Methods for characterization of Streptomyces species," International Journal of Systematic Bacteriology, vol. 16, no. 3, pp. 313-340, 1966.

[29] F. A. Rainey, N. Ward-Rainey, R. M. Kroppenstedt, and E. Stackebrandt, "The genus Nocardiopsis represents a phylogenetically coherent taxon and a distinct actinomycete lineage: proposal of Nocardiopsaceae fam. nov," International Journal of Systematic Bacteriology, vol. 46, no. 4, pp. 1088-1092, 1996.

[30] W. G. Weisburg, S. M. Barns, D. A. Pelletier, and D. J. Lane, "16S ribosomal DNA amplification for phylogenetic study," Journal of Bacteriology, vol. 173, no. 2, pp. 697-703, 1991.

[31] M. A. Innis, D. H. Gelfand, J. J. Sninsky, and T. J. White, PCR Protocols: A Guide to Methods and Application, Academic Press, London, UK, 1990, Academic Press.

[32] F. Boudjelal, A. Zitouni, F. Mathieu, A. Lebrihi, and N. Sabaou, "Taxonomic study and partial characterization of antimicrobial compounds from a moderately halophilic strain of the genus Actinoalloteichus," Brazilian Journal of Microbiology, vol. 42, no. 3, pp. 835-845, 2011.

[33] S. F. Altschul, T. L. Madden, A. A. Schäffer et al., "Gapped BLAST and PSI-BLAST: a new generation of protein database search programs," Nucleic Acids Research, vol. 25, no. 17, pp. 3389-3402, 1997.

[34] S. F. Altschul, W. Gish, W. Miller, E. W. Myers, and D. J. Lipman, "Basic local alignment search tool," Journal of Molecular Biology, vol. 215, no. 3, pp. 403-410, 1990.

[35] J. D. Thompson, D. G. Higgins, and T. J. Gibson, "CLUSTAL $\mathrm{W}$ : improving the sensitivity of progressive multiple sequence alignment through sequence weighting, position-specific gap penalties and weight matrix choice," Nucleic Acids Research, vol. 22, no. 22, pp. 4673-4680, 1994.

[36] K. Tamura, J. Dudley, M. Nei, and S. Kumar, "MEGA4: molecular evolutionary genetics analysis (MEGA) software version 4.0," Molecular Biology and Evolution, vol. 24, no. 8, pp. 15961599, 2007.

[37] K. Tamura, G. Stecher, D. Peterson, A. Filipski, and S. Kumar, "MEGA6: molecular evolutionary genetics analysis version 6.0," Molecular Biology and Evolution, vol. 30, no. 12, pp. 2725-2729, 2013.

[38] N. Yamamoto and G. Lopez, "Bacterial abundance in relation to surface area and organic content of marine sediments," Journal 
of Experimental Marine Biology and Ecology, vol. 90, no. 3, pp. 209-220, 1985.

[39] C. Pedrós-Alió, “Trophic ecology of solar salterns," in Halophilic Microorganisms, vol. 1, Springer, Berlin, Heidelberg, 2004.

[40] P. A. Jose and S. R. D. Jebakumar, "Phylogenetic diversity of actinomycetes cultured from coastal multipond solar saltern in Tuticorin, India," Aquatic Biosystems, vol. 8, article 23, no. 1, 2012.

[41] S. Ballav, S. Kerkar, S. Thomas, and N. Augustine, "Halophilic and halotolerant actinomycetes from a marine saltern of Goa, India producing anti-bacterial metabolites," Journal of Bioscience and Bioengineering, vol. 119, no. 3, pp. 323-330, 2015.

[42] J. Wu, T. Guan, H. Jiang et al., "Diversity of actinobacterial community in saline sediments from Yunnan and Xinjiang, China," Extremophiles, vol. 13, no. 4, pp. 623-632, 2009.

[43] S.-H. Li, Y. Jin, J. Cheng et al., "Gordonia jinhuaensis sp. nov., a novel actinobacterium, isolated from a VBNC (viable but nonculturable) state in pharmaceutical wastewater," Antonie van Leeuwenhoek, International Journal of General and Molecular Microbiology, vol. 106, no. 2, pp. 347-356, 2014.

[44] X. Su, X. Shen, L. Ding, and A. Yokota, "Study on the flocculability of the Arthrobacter sp., an actinomycete resuscitated from the VBNC state," World Journal of Microbiology and Biotechnology, vol. 28, no. 1, pp. 91-97, 2012.

[45] F. L. Rabah, A. Elshafei, M. Saker, B. Cheikh, and H. Hocine, "Screening, isolation and characterization of a novel antimicrobial producing actinomycete, strain RAF10," Biotechnology, vol. 6, no. 4, pp. 489-496, 2007.

[46] C. R. Kokare, K. R. Mahadik, S. S. Kadam, and B. A. Chopade, "Isolation, characterization and antimicrobial activity of marine halophilic Actinopolyspora species AH1 from the west coast of India," Current Science, vol. 86, no. 4, pp. 593-597, 2004.

[47] L. S. Singh, I. Baruah, and T. C. Bora, "Actinomycetes of Loktak habitat: Isolation and screening for antimicrobial activities," Biotechnology, vol. 5, no. 2, pp. 217-221, 2006.

[48] R. Vijayakumar, K. Panneerselvam, C. Muthukumar, N. Thajuddin, A. Panneerselvam, and R. Saravanamuthu, "Optimization of antimicrobial production by a marine actinomycete streptomyces afghaniensis VPTS3-1 isolated from palk strait, East Coast of India," Indian Journal of Microbiology, vol. 52, no. 2, pp. 230-239, 2012.

[49] I. Trabelsi, D. Oves, A. Manteca, O. Genilloud, A. Altalhi, and M. Nour, "Antimicrobial activities of some actinomycetes isolated from different rhizospheric soils in Tunisia," Current Microbiology, vol. 73, no. 2, pp. 220-227, 2016.

[50] C. Prasad, "Bioactive cyclic dipeptides," Peptides, vol. 16, no. 1, pp. 151-164, 1995.

[51] A. Rudi, Y. Kashman, Y. Benayahu, and M. Schleyer, "Amino acid derivatives from the marine sponge Jaspis digonoxea," Journal of Natural Products, vol. 57, no. 6, pp. 829-832, 1994.

[52] K. Ström, J. Sjögren, A. Broberg, and J. Schnürer, "Lactobacillus plantarum MiLAB 393 produces the antifungal cyclic dipeptides cyclo( $L$-Phe- $L$-Pro) and cyclo( $L$-Phe-trans-4-OH- $L$-Pro) and 3-phenyllactic acid," Applied and Environmental Microbiology, vol. 68, no. 9, pp. 4322-4327, 2002.

[53] S. De Rosa, M. Mitova, and G. Tommonaro, "Marine bacteria associated with sponge as source of cyclic peptides," Biomolecular Engineering, vol. 20, no. 4-6, pp. 311-316, 2003.

[54] F. R. Lucietto, P. J. Milne, G. Kilian, C. L. Frost, and M. Van De Venter, "The biological activity of the histidine-containing diketopiperazines cyclo(His-Ala) and cyclo(His-Gly)," Peptides, vol. 27, no. 11, pp. 2706-2714, 2006.
[55] B. Nicholson, G. K. Lloyd, B. R. Miller et al., "NPI-2358 is a tubulin-depolymerizing agent: In-vitro evidence for activity as a tumor vascular-disrupting agent," Anti-Cancer Drugs, vol. 17, no. 1, pp. 25-31, 2006.

[56] S. Sinha, R. Srivastava, E. De Clercq, and R. K. Singh, "Synthesis and antiviral properties of arabino and ribonucleosides of 1,3-dideazaadenine, 4-nitro-1,3-dideazapurine and diketopiperazine," Nucleosides, Nucleotides and Nucleic Acids, vol. 23, no. 12, pp. 1815-1824, 2004.

[57] D. R. Houston, B. Synstad, V. G. H. Eijsink, M. J. R. Stark, I. M. Eggleston, and D. M. F. Van Aalten, "Structure-based exploration of cyclic dipeptide chitinase inhibitors," Journal of Medicinal Chemistry, vol. 47, no. 23, pp. 5713-5720, 2004.

[58] O. S. Kwon, S. H. Park, B. Yun et al., "Cyclo (dehydro ala-L-Leu), an aglucosidase inhibitor from Penicillium sp. F70614," Journal of Antibiotics, vol. 53, pp. 954-958, 2000.

[59] C. C. Cain, D. Lee, R. H. Waldo III et al., "Synergistic antimicrobial activity of metabolites produced by a nonobligate bacterial predator," Antimicrobial Agents and Chemotherapy, vol. 47, no. 7, pp. 2113-2117, 2003.

[60] S. Smaoui, F. Mathieu, L. Elleuch et al., "Taxonomy, purification and chemical characterization of four bioactive compounds from new Streptomyces sp. TN256 strain," World Journal of Microbiology and Biotechnology, vol. 28, no. 3, pp. 793-804, 2012. 

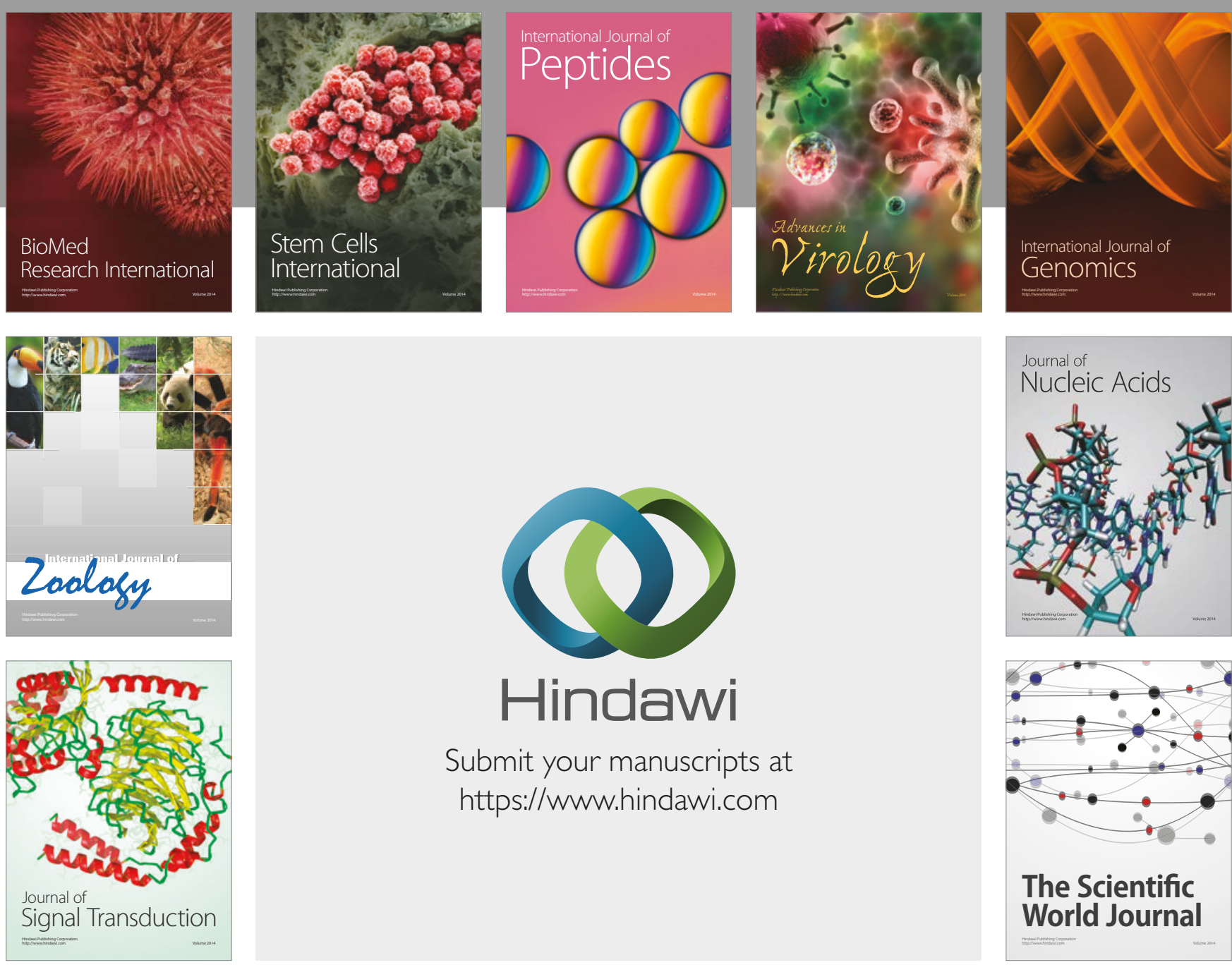

Submit your manuscripts at

https://www.hindawi.com
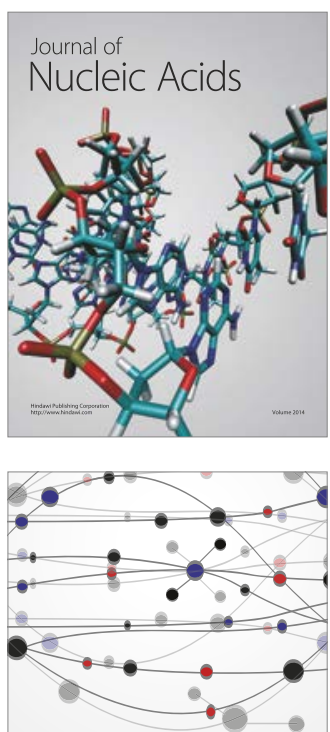

The Scientific World Journal

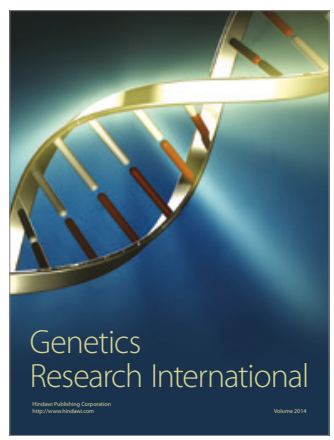

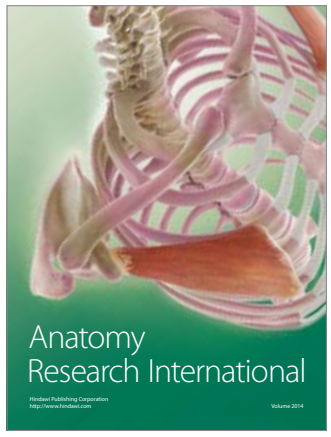

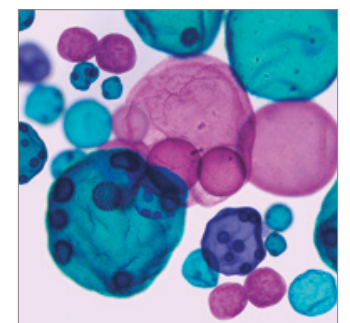

International Journal of Microbiology
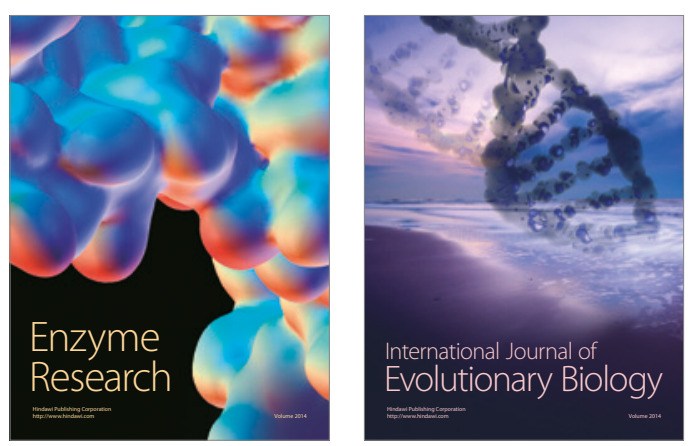
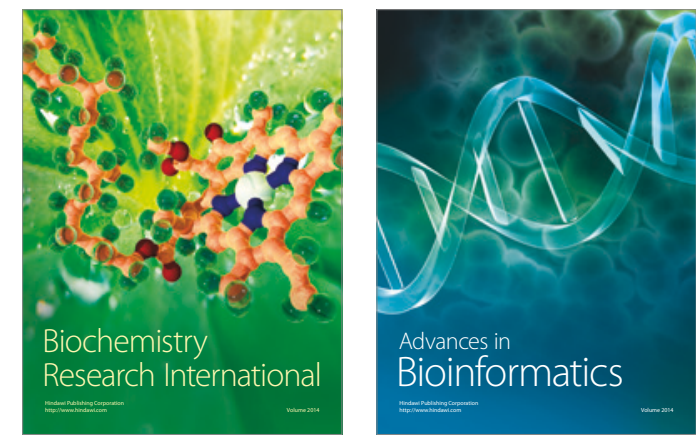

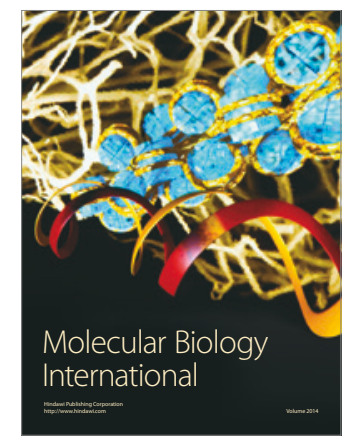

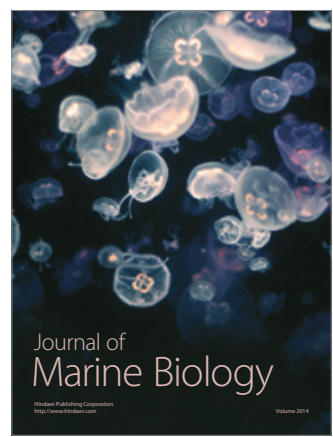

